\title{
LIDERA - UM SISTEMA DE APOIO À PROCURA EFICIENTE DA SUSTENTABILI- DADE NA CONSTRUÇÃO CIVIL NO BRASIL
}

\author{
Manuel Duarte Pinheiro (Ulisboa, Portugal) manuel.pinheiro@tecnico.ulisboa.pt \\ Fernando do Carmo Pereira(UTFPR, Brasil) fernando_docarmo@hotmail.com \\ João Luiz Rissardi (UTFPR, Brasil) luizrissardi@gmail.com \\ Marcos Vinicius Schwanz (UTFPR, Brasil)mvschwanz@gmail.com \\ Jorge Luís Nunes de Góes((UTFPR, Brasil) jgoes@utfpr.edu.br
}

\begin{abstract}
Resumo: O presente trabalho tem como objetivos apresentar o LiderA, que é um sistema de avaliação voluntário de apoio ao desenvolvimento de soluções e avaliação da sustentabilidade no ambiente construído, bem como expor quais ações são consideradas pelo sistema como linhas de boas práticas no âmbito da sustentabilidade. No artigo são também apresentados sumariamente uma das aplicações do sistema no Brasil em dois hotéis no Rio de Janeiro. São discutidas as potencialidades deste sistema como sendo um apoio à procura eficiente da sustentabilidade na construção no Brasil. Analisa-se que implicações tem estes desafios das estratégias da procura da sustentabilidade, sua utilidade ao integrar as abordagens de engenharia de produção, nomeadamente os instrumentos de produção mais limpa e especialmente a ecologia industrial, na procura eficiente da sustentabilidade das edificações hoteleiras, urbanas, industriais e ecoparques.
\end{abstract}

Palavras-chave: Sistema de avaliação ambiental. Construções sustentáveis. Gestão ambiental. Ecologia industrial.

Abstract: This paper aims to present the Lidera, which is a voluntary assessment system to support the development of solutions and evaluation of sustainability in the built environment, as well as expose what actions are considered by the system as lines of good practice in the context of sustainability. This article also briefly presented one of the applications of the system in Brazil, particularly in two hotels in Rio de Janeiro. The potential of this system as an efficient tool is discussed, supporting the search for sustainability in the construction industry in Brazil. It is analyzed the implications of the search for sustainability and the potential challenges for production engineering, including the instruments like cleaner production and industrial ecology for assure and efficient sustainability of hotels, other buildings, urban areas, industrial zones and ecoparks.

Keywords: Environmental assessment system. Sustainable construction. Environmental management. Industrial ecology. 


\section{Introdução}

A partir da evolução no setor da construção civil, o mercado já não se contenta apenas em construir edifícios resistentes e a um baixo custo de acordo com a sua concepção. Nos dias atuais o ato de edificar adotou outra dimensão, engloba diversos fatores, que vão desde elementos com efeitos diretos na própria obra como um sistema de gestão de qualidade na construção, a até o compromisso com as consequências dessa atividade para a sociedade, como a preocupação de se construir em condições ambientalmente corretas.

Nesse sentido tem vindo a surgir várias abordagens para o conseguir e inclusive sistemas que avaliam e certificam a sua procura de bom desempenho ambiental e até de sustentabilidade, entre os sistemas existentes encontra-se um sistema denominado LiderA.

O presente trabalho tem como objetivos apresentar o LiderA, que é um sistema de avaliação voluntário de apoio ao desenvolvimento de soluções e avaliação da sustentabilidade de ambientes construídos, os autores também anseiam expor quais ações são consideradas pelo sistema como linhas de boas práticas no âmbito da sustentabilidade, bem como referenciar a sua relação com as boas práticas de ecologia industrial e desafios que coloca à engenharia da produção.

\section{Revisão de Literatura}

Integrado na reflexão sobre desenvolvimento sustentável, surge em 1993 nos países mais desenvolvidos um movimento internacional
(KIBERT, 2003) que procura definir e implementar o conceito de construção sustentável.

A construção sustentável é um conceito recente e foi nos EUA na Primeira Conferência Mundial sobre Construções Sustentáveis (First World Conference for Sustainable Construction, Tampa, Florida) que Charles Kibert a definiu como "a criação e gestão de um ambiente saudável, tendo em consideração os princípios ecológicos e a utilização eficiente dos recursos". Kibert também sugeriu os seis princípios para a sustentabilidade na construção: minimizar o consumo de recursos, maximizar a reutilização dos recursos, utilizar recursos renováveis e recicláveis, proteger o ambiente natural, criar um ambiente saudável e não tóxico, e por fim fomentar a qualidade ao criar o ambiente construído (PEREIRA, 2009; PINHEIRO, 2006).

A aplicação desta abordagem de sustentabilidade na construção tem sido associada a múltiplas dimensões, nomeadamente e edifícios, zonas urbanas, cidade e até parques industriais, bem como integra desafios não só para quem projeta, constrói e gere. Mas para a toda a cadeia de produção, em alguns casos conjugado com lógica de ecologia industrial (PINHEIRO, 2014).

Uma das áreas desenvolvidas onde este conceitos ganham dimensão são os eco-parques (LUTZ, et al., 2013) nomeadamente no Rio de Janeiro onde a legislação de desenvolvimento industrial e urbano potencia esta abordagem (VEIGA E MAGRINI, 2009).

Um vocabulário único (KBERT, 2013) está a emergir para descrever conceitos relacionados 
com a sustentabilidade e as mudanças ambientais globais. Termos como o princípio da precaução, pegada ecológica, mochila ecológica, Fator 4 e Fator 10 (mudanças de 4 ou 10 vezes), biomimetismo, biofilia (imitando a natureza), Natural Step, eco-eficiência, economia ecológica, estão a surgir como descrição dos conceitos filosóficos e científicos fundamentais que se aplicam a uma mudança de paradigma em direção à sustentabilidade.

Depois de uma análise dos principais mitos sobre sustentabilidade na construção, PINHEIRO (2003) destacou que cada vez mais esses mitos não correspondem com a realidade em muitos países, sendo que o modelo e paradigma na construção e ambiente está a mudar para uma logica win-win (PINHEIRO, 2014). Afirma ainda que por meio de um sistema de avaliação é possível mensurar de forma prática e reconhecer uma construção sustentável e, atribuindo em caso de desempenho sustentável comprovado, uma certificação ambiental.

No geral, o sistema de avaliação ambiental dos edifícios (ou ambientes construídos) constitui uma forma de avaliar o seu desempenho ambiental (ou sustentabilidade) face a um conjunto de critérios explícitos (PLESSIS E COLE, 2011), dispondo-se, tipicamente, de três grandes tipos de componentes: (1) Conjunto declarado de critérios (prescritivos ou de desempenho) ambiental, organizado de modo lógico numa estrutura apelativa; (2) Atribuição de um número de critérios de pontos por cada desempenho, isto é, uma escala que ao atingir um determinado nível obtém-se determinada pontuação; (3) Modo de agregar, quer seja por ponderação explícita ou não, para dar a sua importância, de modo a obter-se um valor agregado e global em termos finais, atribuindo uma pontuação total ao desempenho ambiental do edifício ou empreendimento.

Alguns dos principais sistemas de avaliação presentes no mundo são: o BREEAM (Reino Unido), o LEED (Estados Unidos), o NABERS (Austrália), o BEPAC (Canadá), o HQE (França) e o CASBEE (Japão). Segundo Leite (2011) os dois sistemas mais utilizados no Brasil são o LEED e o AQUA (Alta Qualidade Ambiental) que é baseada no HQE (PINHEIRO, 2006; PINHEIRO, 2014).

O LiderA é um sistema de apoio, avaliação e contribuição para o desenvolvimento da sustentabilidade, quer ao nível dos edifícios, quer ao nível dos espaços exteriores e zonas construídas.

Em 2000 foram iniciadas pesquisas preliminares de investigação desse sistema, sendo fundado oficialmente em Portugal no ano de 2005, pelo Doutor Manuel Duarte Pinheiro, emitindo suas primeiras certificações em 2007, atualmente tem vindo a ser aplicado em vários países lusófonos.

\section{Metodologia}

A metodologia utilizada neste trabalho assenta na sistematização dos conceitos sobre construções sustentáveis e sistemas de avaliação ambiental, tendo um enfoque maior em publicações de artigos sobre o sistema LiderA, onde se revê e apresenta o sistema, especifica a sua aplicação em dois casos e discute a importância de na sua aplicação nomeadamente integrar 
o conceito da ecologia industrial e boas práticas de engenharia de produção.

\section{Sistema LiderA - Revisão de Litera- tura}

\subsection{Apresentação do Sistema LiderA}

O nome do sistema LiderA é acrónimo de Liderar pelo Ambiente para a construção sustentável, é dentro de aspecto que ele procura reformular o ambiente na construção, por meio da orientação e da avaliação do nível de busca pela sustentabilidade. O LiderA é um sistema voluntário que apoia projetos sustentáveis e certifica produtos do mercado da construção, como por exemplo, edifícios, materiais, empreendimentos, entre outros, desde a fase de concepção do projeto até a utilização.

Este sistema busca ser uma marcada distintiva, Business to Business, do nível de desempenho ambiental e da sustentabilidade da construção em Portugal e nos Países de Língua Portuguesa, como é o caso do Brasil onde o LiderA está presente desde 2013 e á avaliou vários empreendimentos (incluindo uma creche) e dois hotéis na cidade do Rio de Janeiro.

\subsection{Organização}

O Sistema LiderA parte do princípio de que a busca pela sustentabilidade deve ser fundamentada em ações concretas que resultem efetivamente na obtenção de processos e produtos menos agressivos ao meio ambiente, portanto, é neste anseio que o sistema se organiza em um conjunto de seis princípios de bom desempenho ambiental, sendo eles: Valorizar a di- nâmica local e promover uma adequada integração; Fomentar a eficiência no uso dos recursos; Reduzir o impacto das cargas (quer em valor, quer em toxicidade); Assegurar o serviço, no caso dos edifícios foca-se na qualidade do ambiente, focada no conforto ambiental; Fomentar as vivências socioeconômicas sustentáveis; Assegurar a melhor utilização sustentável dos ambientes construídos, por meio da gestão ambiental e da inovação (PINHEIRO, 2010).

As seis vertentes que orientam as avaliações são traduzidas em 22 áreas, como mostra no Gráfico 1.

Com o anseio de orientar e avaliar o desempenho nos países lusófonos, é adotado um conjunto de 22 Critérios que operacionalizam os aspectos a considerar em cada área, nos quais se avaliam os ambientes construídos em função do seu desempenho, no caminho para a sustentabilidade.

São estabelecidos para cada tipo de utilização e para cada critério, níveis de desempenho que possibilitam indicar se a solução é ou não sustentável, estes níveis são indicados de forma numérica e posteriormente são transformados em classes que vão de $\mathrm{G}$ a $\mathrm{A}++$, visando um melhor entendimento da avaliação. O Gráfico 2 apresenta os níveis de desempenho global atribuídos no final de uma avaliação.

Para o Sistema LiderA o grau de sustentabilidade global é mensurável numa função quantitativa (0 a 10) classes de bom desempenho crescentes: desde a prática (E) a Classes C (superior a $25 \%$ à prática), B $(37,5 \%)$ e $\mathrm{A}$ (50\% ou fator 2). Na melhor Classe de desem- 
penho existe, par além da Classe A, a Classe $\mathrm{A}+$, associada a um fator de melhoria de 4 e a Classe A++ associada a um fator de melhoria de 10 face à situação inicial considerada.

Para obter um valor agregado, a classificação final conjugada é obtida por meio da pondera- ção das 22 áreas. Para o efeito, por meio de inquirição e consenso, foram obtidas as ponderações para cada uma das áreas, sendo as áreas de maior importância a energia, a água e os materiais representando cada uma $10 \%$.

\section{GRAFICO 1: ORGANIZAÇÃO DO SISTEMA LIDERA}

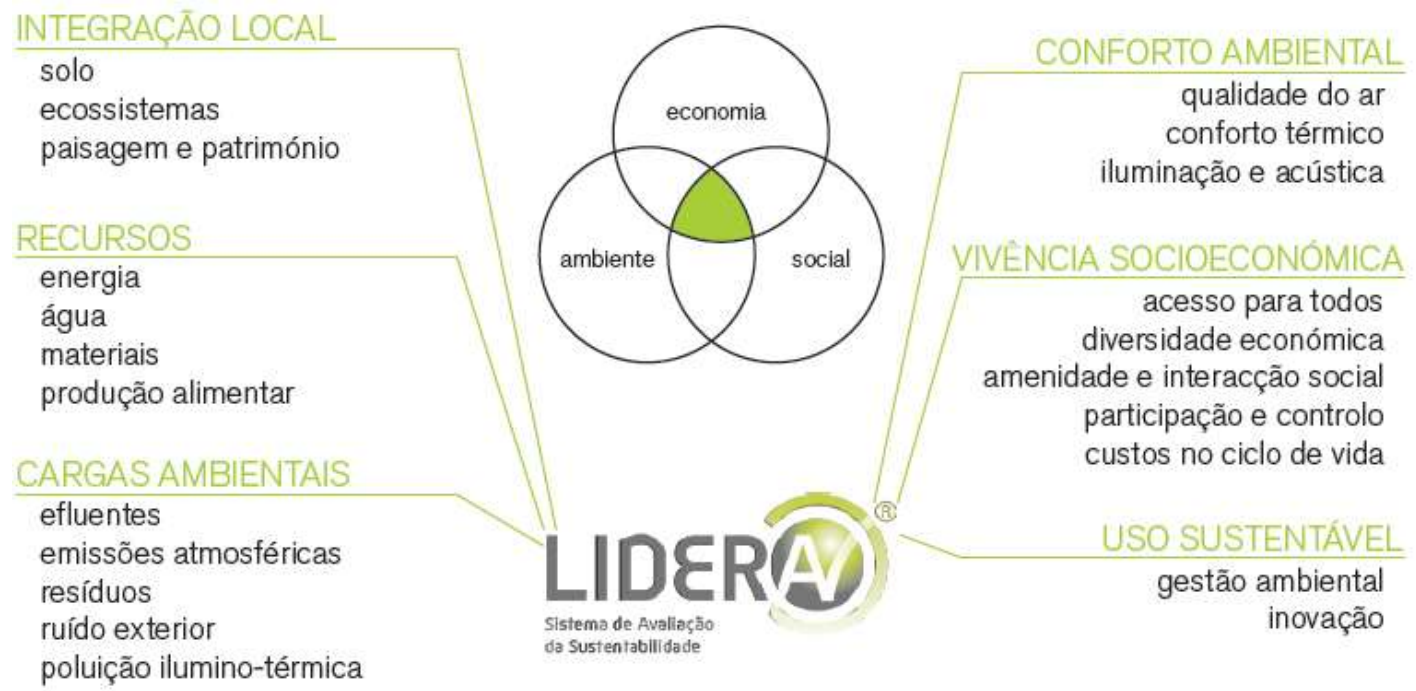

Fonte: PINHEIRO, 2011

A contabilização por vertentes posiciona como mais relevante os recursos com $32 \%$ do peso, seguido da vivência socioeconómica (19\%), conforto ambiental (15 \%), integração local(14\%), cargas ambientais (12\%) e por fim a gestão ambiental (8\%) do edificado.

\section{GRÁFICO 2: NÍVEIS DE DESEMPENHO GLOBAL}

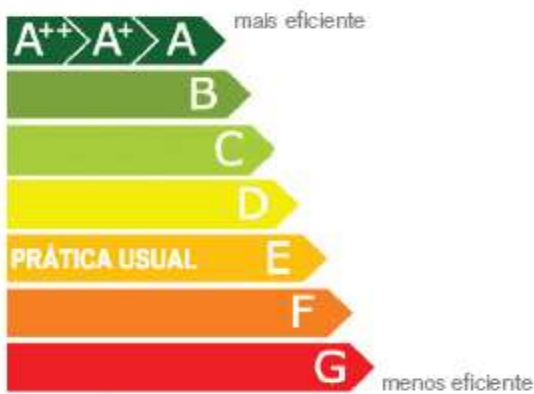

Fonte: PINHEIRO, 2011
A ponderação do nível de desempenho global é determinada a partir da soma das ponderações obtidas sucessivamente ao nível de desempenho dos critérios, das áreas e das vertentes.

\subsection{Linhas de Boas Práticas}

A parametrização para cada critério segue a melhoria das práticas existentes, ou a referência aos valores de boas práticas, tal como é usual nos sistemas internacionais. A Tabela 1 apresenta os critérios adotados pelo LiderA, qual a sua porcentagem na avaliação que cada um possui, e indica a qual área e vertente ele pertence.

Segundo Pinheiro (2010), a construção tem um importante impacto ambiental, econômico e 
social, contudo pode ser igualmente encarada como uma oportunidade para promover boas práticas nestas três dimensões, logo a procura pelo equilíbrio nas perspectivas ambientais, econômicas e sociais resulta na busca da sustentabilidade.

É neste contexto que as propostas consideradas são baseadas nas boas práticas, quer ao nível da arquitetura, quer ao nível da construção, para que uma vez desenvolvidas e corretamente aplicadas, os edifícios alcancem uma boa qualidade arquitetônica de conforto e salubridade para os utilizadores e um bom desempenho ambiental, especificamente na procura da sustentabilidade de forma a ser certificado (classes de certificação do Sistema LiderA: C, $\mathrm{B}, \mathrm{A}, \mathrm{A}+$ ou $\mathrm{A}++)$.

Cada critério do sistema LiderA remete à linhas de boas práticas, ou seja, o que se espera do edifício, ou áreas avaliadas, afim deste obter uma boa classificação. As boas práticas referentes a cada critério consideradas pelo sistema são, por exemplo:

- Valorização Territorial (A1): Promover aglomerados urbanos compactos (média densidade), minimizando a expansão suburbana; Promover a adoção de vários usos do solo simultâneos; Promover a construção de redes de infraestruturas locais; Minimizar a erosão e promover a permeabilidade do solo.

- Valorização Ecológica (A2): Minimizar a destruição ou alteração da fauna e flora local; Promover a integração de espaços e estruturas verdes nos aglomerados urbanos.
- Valorização Paisagística (A3): Adequar as intervenções às condições naturais locais (topografia, fauna, flora, estruturas verdes); Adequar as intervenções à envolvente construída local (edificado, infraestruturas, espaços público); Respeitar os valores, tradições e técnicas construtivas locais.

- Gestão da Energia (A4): Diminuição das necessidades nominais de energia - otimizar o ciclo da energia; Construir com base em princípios bioclimáticos; Incentivar a utilização de sistemas de fontes renováveis (solares térmicos, fotovoltaicos, eólicos, geotérmico, biomassa) adaptados às condições locais.

- Gestão da Água (A5): Garantir o ciclo da água nos ecossistemas locais; Desenvolver o acesso a água potável - promover a qualidade da água; Otimizar o consumo de água primária proveniente da rede de abastecimento pública, de poços, de fontes ou de furos; Recolha e utilização de águas pluviais; Reutilização de águas tratadas para consumos secundários; Promover a introdução de sistemas waterless; Garantir a higiene e salubridade evitando a existência de locais com águas estagnadas ou poluídas.

- Gestão dos Materiais (A6): Fomentar o uso de materiais locais e materiais reciclados; Conjugação de materiais de modo a obter soluções duráveis; Adoção de materiais e técnicas construtivas que promovam a conservação de energia.

- Produção local de alimentos (A7): Pro- 
mover a produção local de alimentos de origem animal e/ou vegetal.

- Gestão dos Efluentes (A8): Desenvolver sistemas de tratamento de águas residuais locais; Promover a recolha, separação e tratamento das águas residuais e posterior reutilização das mesmas para consumos secundários.

- Gestão das Emissões Atmosféricas (A9): Eliminar ou diminuir soluções que recorram ao processo de combustão; Evitar a utilização de soluções que impliquem a emissão de substâncias acidificantes; Promover a aplicação de sistemas e equipamentos ou ventilação natural que evitem a acumulação de partículas nocivas (poeiras, fungos, bactérias).

- Gestão dos Resíduos (A10): Promover o tratamento local de resíduos; Reduzir a produção de resíduos e aumentar a percentagem de resíduos valorizados na construção, operação e demolição; Implementar a compostagem de resíduos orgânicos ou a produção de energia da biomassa como forma de tratamento de resíduos; Reduzir a produção de resíduos perigosos, otimizar as suas condições de armazenamento e deposição final.

- Gestão do ruído (A11): Controlo das fontes de ruído para o exterior; Reduzir os níveis de ruído exteriores para níveis ambientalmente aceitáveis.

- Gestão ilumino-térmica (A12): Reduzir o efeito da "ilha de calor" e da poluição ilumino-térmica.

- Gestão da Qualidade do Ar (A13): Im- plementar a ventilação natural no edifício, promover a ventilação cruzada; Promover a circulação e ventilação do ar nos espaços envolventes ao edifício; Implementar medidas com vista a redução de contaminações no ar (COV's, micro-contaminações, odores, gases); Garantir a salubridade dos espaços interiores assegurando a sua proteção a doenças.

- Gestão do Conforto Térmico (A14): Desenvolver estratégias de desempenho passivo com vista a assegurar o conforto térmico dos utilizadores tanto internamente como externamente; Introduzir e assegurar a aplicação de isolamentos térmicos adequados no edificado (paredes, cobertura, pavimentos); Assegurar boas condições de conforto térmico nos espaços públicos exteriores (orientação e exposição solar, sombreamento, ventilação, evaporação).

- Gestão de outras condições de Conforto (A15): Promover e assegurar bons níveis de iluminação natural no interior e exterior do edificado, por meio da adoção de técnicas de desempenho passivo; Promover a introdução ponderada de iluminação artificial no edificado assegurando bons níveis de iluminação artificial no interior do edificado, nos locais em que tal seja necessário; Assegurar bons níveis de iluminação artificial no exterior do edificado, em especial nos espaços de concentração da população; Localização correta do edificado de forma a garantir a proteção a fontes de ruído locais e assegurar bons níveis de conforto sonoro no interior dos espaços, 
aplicando isolamentos acústicos adequados; Adotar organizações espaciais que favoreçam os usos dos espaços considerados.

\section{- Contribuir para acessibilidade (A16):}

Promover a construção de infraestruturas que facilitem os deslocamentos cotidianos que servem de apoio aos meios de transporte locais (estradas, abrigos, passeios, faixas de pedestres, ciclovias, estações); Oferecer uma variedade de soluções e espaços públicos nas imediações do edificado que facilitem e incentivem a atividade física e favoreçam os deslocamentos de baixo impacto; Promover a criação e favorecer a utilização de transportes coletivos que abranjam o maior número de utilizadores possível; Assegurar a mobilidade e o acesso a pessoas com mobilidade condicionada, quer seja nos espaços interiores, quer nos exteriores, evitando essencialmente as barreiras arquitetônicas.

\section{- Contribuir para a Dinâmica Econômica}

(A17): Concepção de soluções espaciais, redes e sistemas auxiliares flexíveis, modulares e ajustáveis às necessidades evolutivas locais; Criar soluções espaciais e arquitetônicas que permitam criar valor no local e no mercado imobiliário; Adotar soluções que favoreçam trocas comerciais que potenciem o comércio local; Tipologias de soluções, produtos e espaços adequados a diferentes classes sociais; Promover a localização de postos de trabalho nos ambientes construídos locais, com ênfase na empregabilidade da população local; Promover a igualdade de género e de esta- tuto social; Criação de empregos qualificados e formação da população local.

- Contribuir para as Amenidades (A18): Promover a valorização das amenidades locais fomentando a sua presença e criação, a sua manutenção e a sua proximidade aos usuários como uma prioridade para os ambientes locais; Promover atividades, espaços e soluções que solicitem a participação da população local com a comunidade envolvente.

- Condições de controle (A19): Aplicação de medidas de controle e inibição da criminalidade e vandalismo no edificado e espaços construídos (iluminação, vigilância, permeabilidade do espaço e campos de visão); Fomentar o controle do nível do conforto (temperatura, humidade, ventilação, sombreamento e iluminação), adequando as condições do edificado às estações de Verão e Inverno; Adequar as intervenções aos riscos naturais existentes e evitar os riscos inerentes às soluções arquitetônicas adotadas; Prever medidas que permitam melhorar as condições de higiene locais, garantindo a salubridade dos espaços construídos de forma a evitar riscos associados a doenças contagiosas; Promover a participação ativa dos cidadãos com intuito de melhorar a sua qualidade de vida, as suas condições de conforto e o usufruto ou a vivência do ambiente construído; Promover a participação ativa dos cidadãos em igualdade de género e de estatuto social.

- Contribuir para os Baixos Custos no 


\section{ReLAInEF}

Ciclo de Vida (A20): Maximizar a rentabilidade do edifício e ambientes construídos e minimizar a sua manutenção, promovendo baixos custos no ciclo de vida dos elementos constituintes da comunidade; Escolha de materiais, equipamentos e soluções construtivas simples, duráveis e resistentes, que possam posteriormente ser reaproveitados e reciclados; Ponderar a adopção de soluções flexíveis, que permitam uma fácil adaptação a diferentes realidades, sem o encargo de custos adicionais.

- Promover a Utilização e Gestão (A21): Contribuir para a formação da população em relação à utilização dos espaços edificados e do desempenho ambiental dos mesmos; Criar modos de utilização simplificados que permitam potenciar os níveis de desempenho ambiental quer no edifica- do, quer nos espaços exteriores; Introduzir modos de gestão simplificados que permitam assegurar a adequada manutenção, utilização e operação do edificado e dos espaços exteriores.

- Promover a Inovação (A22): Reforçar e incentivar a aplicação de soluções que promovam a sustentabilidade e a adopção de medidas inovadoras que melhorem o desempenho ambiental; Aplicação de soluções inovadoras que contribuam para a melhoria da qualidade de vida da população local.

As funções de desempenho em cada critério vão de 0 a 10 (onde 1 é prática usual) e sendo ajustada a realidade de cada região cada uso e fase da aplicação (projeto, construção, operação, reabilitação).

TABELA 1: VERTENTES, ÁREAS E CRITÉRIOS DO LIDERA NA VERSÃO INTERNACIONAL

\begin{tabular}{|c|c|c|c|c|}
\hline Vertente & Área & $\mathbf{N}^{0}$ de critério & Critério & Wi \\
\hline \multirow{3}{*}{$\begin{array}{c}\text { Integração } \\
\text { Local }\end{array}$} & Solo & A1 & Valorização Territorial & $5 \%$ \\
\hline & Ecossistemas naturais & A2 & Valorização Ecológica & $5 \%$ \\
\hline & Paisagem e Património & A3 & Valorização Paisagística & $4 \%$ \\
\hline \multirow[t]{4}{*}{ Recursos } & Energia & A4 & Gestão da Energia & $10 \%$ \\
\hline & Água & A5 & Gestão da Água & $10 \%$ \\
\hline & Materiais & A6 & Gestão dos Materiais & $10 \%$ \\
\hline & Alimentares & A7 & Produção local de alimentos & $2 \%$ \\
\hline \multirow{5}{*}{$\begin{array}{c}\text { Cargas Am- } \\
\text { bientais }\end{array}$} & Efluentes & A8 & Gestão dos Efluentes & $3 \%$ \\
\hline & Emissões Atmosféricas & A9 & Gestão das Emissões Atmosféricas & $2 \%$ \\
\hline & Resíduos & A10 & Gestão dos Resíduos & $3 \%$ \\
\hline & Ruído Exterior & A11 & Gestão do ruído & $3 \%$ \\
\hline & $\begin{array}{c}\text { Poluição Ilumino- } \\
\text { térmica }\end{array}$ & A12 & Gestão ilumino-térmica & $1 \%$ \\
\hline Conforto & Qualidade do Ar & A13 & Gestão da Qualidade do Ar & $5 \%$ \\
\hline
\end{tabular}

Revista Latino-Americana de Inovação e Engenharia de Produção Vol. 2, n. 2. Jan./jun. 2014 


\section{ReLAInEF}

\begin{tabular}{|c|c|c|c|c|}
\hline Vertente & Área & $N^{0}$ de critério & Critério & Wi \\
\hline \multirow[t]{2}{*}{ Ambiental } & Conforto Térmico & A14 & Gestão do Conforto Térmico & $5 \%$ \\
\hline & Iluminação e Acústica & A15 & Gestão de outras condições de Conforto & $5 \%$ \\
\hline \multirow{5}{*}{$\begin{array}{c}\text { Vivência } \\
\text { Sócio Eco- } \\
\text { nômico }\end{array}$} & Acesso para todos & A16 & Contribuir para acessibilidade & $3 \%$ \\
\hline & Diversidade Econômica & A17 & Contribuir para a Dinâmica Econômica & $4 \%$ \\
\hline & $\begin{array}{c}\text { Amenidades e Interação } \\
\text { Social }\end{array}$ & A18 & Contribuir para as Amenidades & $4 \%$ \\
\hline & Participação e Controle & A19 & Condições de controle & $3 \%$ \\
\hline & Custos no Ciclo de Vida & A20 & Contribuir para os Baixos Custos no & $5 \%$ \\
\hline \multirow{2}{*}{$\begin{array}{c}\text { Gestão Am- } \\
\text { biental e } \\
\text { Inovonão }\end{array}$} & Uso Sustentável & A21 & Promover a Utilização e Gestão & $4 \%$ \\
\hline & Inovação & A22 & Promover a Inovação & $4 \%$ \\
\hline
\end{tabular}

Fonte: Elaborado pelos autores

\section{Resultados: Aplicação do Sistema LiderA no Brasil - Exemplos}

Para exemplificar a aplicação do LiderA no Brasil foi realizado um levantamento especifico dos níveis de desempenho de dois edifícios, o Hotel Marina All Suites e o Hotel Marina Palace. Ambos se encontram em fase de operação e estão localizados no Rio de Janeiro, bairro do Leblon, zona sul, onde se apresentam na área do turismo carioca, como alguns dos me- lhores serviços hoteleiros locais.

O Hotel Marina All Suites possui 19 pisos de altura, e conta com 39 suítes, uma sala executiva, um espaço lounge, uma web room, um home theater, um fitness center, uma sala de massagens, uma piscina interior, uma sauna, um restaurante, um bar, um serviço de lavanderia e uma zona de recepção e manutenção. Totalizando uma área bruta de $3599 \mathrm{~m}^{2}$ de construção, (GALÃO, 2013).

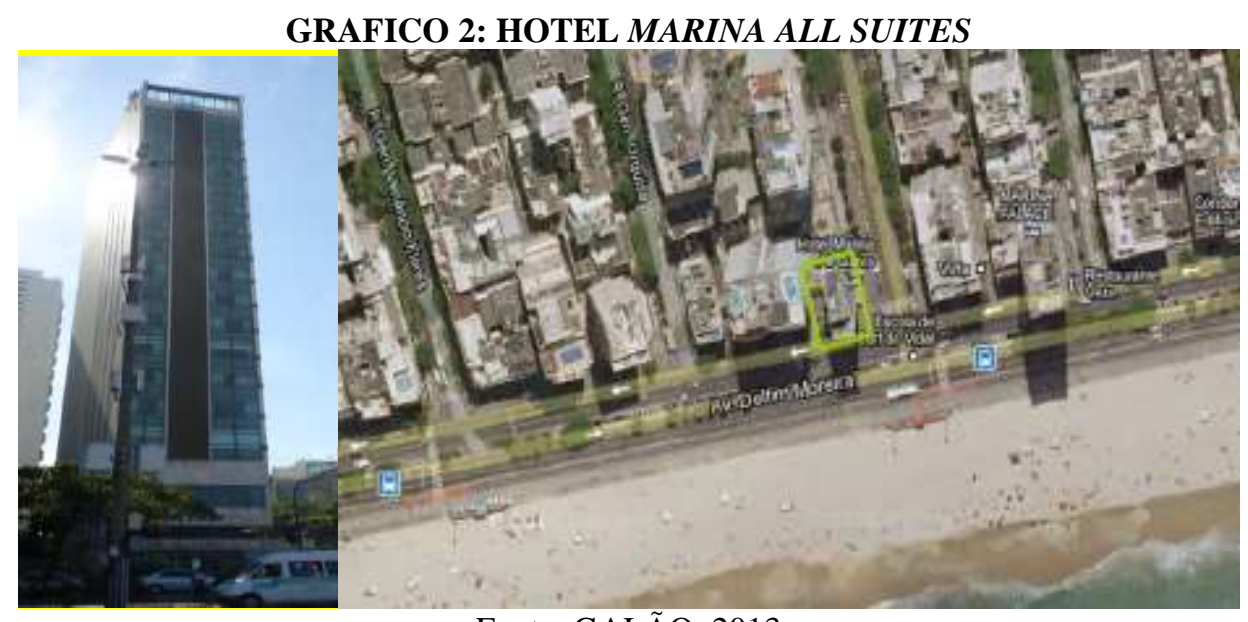

Fonte: GALÃO, 2013 


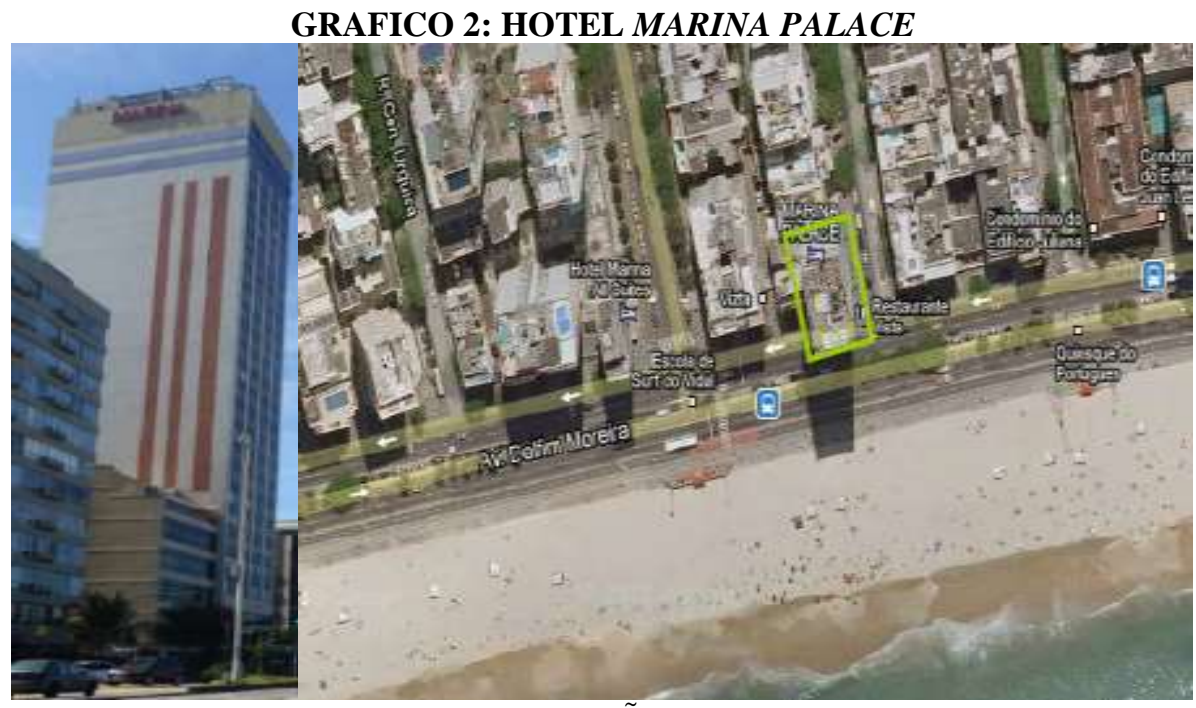

Fonte: GALÃO, 2013

\section{Resultados}

Já o Hotel Marina Palace possui 29 pisos de altura, contando com 150 quartos, 9 salões para eventos, um business center, um restaurante, um bar, uma piscina exterior, sauna, fitness center, beauty center, uma lavanderia e uma zona de recepção e manutenção. Totalizando uma área bruta de $9965 \mathrm{~m}^{2}$ de construção (GALÃO, 2013).

A aplicação do sistema aos dois casos inicia-se por (1) caracterizar hotéis, (2) levantamento dos dados de forma a cada critério identificar quais são as soluções construtivas existentes (mapas, verificação no local, entre outros). E se possível (3) qual é o seu nível de desempenho, que resulta dessas soluções conjugado com o modo de utilização, (4) compara-se os dados obtidos e verificados com o quadro de limiares para cada critério que dispõe com a função que interliga as componentes construtivas (prescritiva) e níveis de desempenho às classes fatoriais definindo qual é classe $(\mathrm{G}$ a
$\mathrm{A}++)$.

Após o cálculo para todos os critérios com base na ponderação (6) obtém-se a classe global de desempenho. Após esta fase pode (7) ser analisado de que forma se pode melhorar e suas implicações, desde logo no desempenho e (8) nos aspectos económicos, permitindo assim propor melhorias de forma fundamentada.

Dado que seria difícil apresentar para todos o critérios apresenta-se o exemplo na gestão da energia (critério A12) na componente construtiva de que forma cada um dos, hotéis estão ou não orientados segundo princípios bioclimáticos, se permitem potenciar a ventilação natural, se dispõe de equipamentos eficientes. Os dados obtidos permitem verificar aspectos comuns nos dois edifícios (Quadro 2) bem como modos de utilização diferenciados.

Diga-se também que, nesta área, entra como fator positivo o fato de serem edifícios mais altos que os do entorno, pois faz com que beneficiem de maior teor de luz natural, condição acrescida por não serem contíguos a nenhum 


\section{ReLAInEF?}

outro prédio. Contudo esta situação pode resultar num aquecimento natural (por meio do sol) desnecessário para o conforto interior de um hotel em zona tropical, onde as condições a corrigir serão, na prática, totalmente respectivas ao calor que se sente e não às temperaturas frias. Já de real carácter negativo prevalecem as questões associadas às energias renováveis, pois não existe qualquer tipo de uso ou produção deste tipo de fonte energética.

Em temos de desempenho energético analisese se ou seu desempenho energético pelo serviço (consumo de energia por dormida, por exemplo, em kWh/hóspede/noite) é superior ou não à prática de referência

$\mathrm{kWh} /$ hóspede/noite), tendo-se obtido uma classe A para Marina Palace o e A+ para o Marina All Suites. Entre as oportunidades de melhoria é de referir a possibilidade de ter um sistema de painéis para aquecer a água para banhos e outros fins por meio de energia renovável, bem como a importância da cadeia de fornecimento, vir a conhecer esta procura de sustentabilidade e assegurar o fornecimento de produtos com melhore desempenho ambiental e de procura da sustentabilidade.

TABELA 1: VERTENTES, ÁREAS E CRITÉRIOS DO LIDERA NA VERSÃO INTERNACIONAL

\begin{tabular}{|c|c|c|c|c|}
\hline Vertente & Área & $\mathbf{N}^{0}$ de critério & Critério & Wi \\
\hline \multirow{3}{*}{$\begin{array}{c}\text { Integração } \\
\text { Local }\end{array}$} & Solo & A1 & Valorização Territorial & $5 \%$ \\
\hline & Ecossistemas naturais & A2 & Valorização Ecológica & $5 \%$ \\
\hline & Paisagem e Património & A3 & Valorização Paisagística & $4 \%$ \\
\hline \multirow{4}{*}{ Recursos } & Energia & A4 & Gestão da Energia & $10 \%$ \\
\hline & Água & A5 & Gestão da Água & $10 \%$ \\
\hline & Materiais & A6 & Gestão dos Materiais & $10 \%$ \\
\hline & Alimentares & A7 & Produção local de alimentos & $2 \%$ \\
\hline \multirow{5}{*}{$\begin{array}{l}\text { Cargas Ambi- } \\
\text { entais }\end{array}$} & Efluentes & A8 & Gestão dos Efluentes & $3 \%$ \\
\hline & Emissões Atmosféricas & A9 & Gestão das Emissões Atmosféricas & $2 \%$ \\
\hline & Resíduos & A10 & Gestão dos Resíduos & $3 \%$ \\
\hline & Ruído Exterior & A11 & Gestão do ruído & $3 \%$ \\
\hline & Poluição Ilumino-térmica & A12 & Gestão ilumino-térmica & $1 \%$ \\
\hline \multirow{3}{*}{$\begin{array}{l}\text { Conforto } \\
\text { Ambiental }\end{array}$} & Qualidade do Ar & A13 & Gestão da Qualidade do Ar & $5 \%$ \\
\hline & Conforto Térmico & A14 & Gestão do Conforto Térmico & $5 \%$ \\
\hline & Iluminação e Acústica & A15 & Gestão de outras condições de Conforto & $5 \%$ \\
\hline Vivência & Acesso para todos & A16 & Contribuir para acessibilidade & $3 \%$ \\
\hline
\end{tabular}




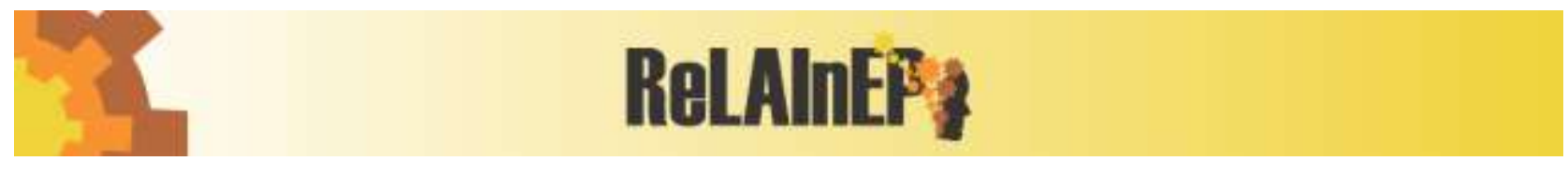

\begin{tabular}{|c|c|c|c|c|}
\hline Vertente & Área & $\mathbf{N}^{0}$ de critério & Critério & Wi \\
\hline \multirow{4}{*}{$\begin{array}{l}\text { SócioEconô- } \\
\text { mica }\end{array}$} & Diversidade Econômica & A17 & Contribuir para a Dinâmica Econômica & $4 \%$ \\
\hline & Amenidades e Interação Social & A18 & Contribuir para as Amenidades & $4 \%$ \\
\hline & Participação e Controle & A19 & Condições de controle & $3 \%$ \\
\hline & Custos no Ciclo de Vida & A 20 & $\begin{array}{c}\text { Contribuir para os Baixos Custos no } \\
\text { Ciclo de Vida }\end{array}$ & $5 \%$ \\
\hline \multirow{2}{*}{$\begin{array}{c}\text { Gestão Ambi- } \\
\text { ental e Inova- } \\
\text { ção }\end{array}$} & Uso Sustentável & A21 & Promover a Utilização e Gestão & $4 \%$ \\
\hline & Inovação & A22 & Promover a Inovação & $4 \%$ \\
\hline
\end{tabular}

Fonte: Elaborado pelos autores

A análise final ponderada da totalidade dos critérios aponta para que os dois seja um classe $\mathrm{A}$, isto é $50 \%$ melhor que a prática de referência. Para Galão (2013), os dois hotéis têm potencial de progressão para a classe seguinte (classe $\mathrm{A}+$ ), caso implementem certas medidas de melhoria. O hotel Marina Palace apresenta, a nível internacional e brasileiro, muito boas práticas nas áreas da energia e água mas desempenhos fracos na área dos resíduos. No hotel Marina All Suites o comportamento é similar, exceto na área da água onde apresenta um desempenho muito reduzido (classe F) decorrente do modo de utilização.

\section{Discussão de Resultados e Potencia- lidades}

A aplicação do LiderA nomeadamente os critérios em que os hotéis apresentam melhor desempenho decorre da combinação de três componentes de aspectos construtivos (orientação, soluções construtivas, materiais), os sistemas que se adotam (iluminação, ar condicionado, etc.) e nos modos de gestão por meio do uso do critério A21 de uso sustentável.

Esta lógica integrando o modo de gestão dos edifícios e zonas e os comportamentos permite assim ter uma visão integrada e potenciar e promover o envolvimento dos utilizadores sendo uma fator chave para assegurar bons desempenhos e resultados satisfatórios.

Para o caso dos Hotéis o LiderA procurou ajustar a escala de desempenho ao tipo de hotéis e condições locais o que potencia a sua aplicabilidade e utilidade em cada local e promovendo boas soluções que usam materiais e tecnologias ajustadas ou locais.

Acresce que ao definir que a procura da sustentabilidade numa escala alargada e não apenas o que se pode fazer imediatamente. Isto é a prática usual é uma classe E (valor 1 numa escala que vai até 10 ), em que o melhor desempenho é 10 (isto é A++, significa uma melhoria de 10 vezes. Ou seja, na energia pode significar quase zero de energia e até edifícios que produzem mais energia que necessitam, apostando no desempenho passivo, sistemas eficiente, comportamentos ajustados e utilização de renováveis. No limite o fator de melhoria 10 é que 
assegura mesmo a sustentabilidade a longo prazo.

Ao utilizar esta escala ambiciosa sinaliza que o grau atingido é um passo para a efetiva sustentabilidade, por um lado esta lógica pode reduzir o interesse porque teoricamente os promotores querem ter os edifícios que são os melhores (a melhor classe) nessa lógica é difícil terão edifícios que podem ter classes C, B , A. Mas por outro lado dão sinais mais efetivos e permitem assumir que é um classe $\mathrm{A}$ ou $\mathrm{A}+$ porque essa equilibra a dimensão ambiental e socioeconômica. A vantagem é que também desafia os projetistas, promotores e agentes a procurar ter avanços mais substanciais.

O LiderA como sistema permite avaliar não só a componente ambiental em sentido mais limitado, usualmente designada por "green" mas inclui aspectos sociais, nomeadamente vivencias sociais (acessibilidade, dinâmica econômica (incluindo trabalho local), amenidades, ...) e econômicos numa lógica de custos de ciclo de vida. Ou seja potência mais que apenas um desempenho ambiental mas o equilíbrio ambiental, econômico e social, assumindo de forma eficiente a sustentabilidade. Sendo por isso pode ser uma abordagem equilibrada (balizando aspectos ambientais, econômicos e sociais) para a realidade brasileira que importa desenvolver e aplicar cada vez mais.

Neste domínio a procura de abordagens de construção sustentável desafia o projeto (para uma abordagem mais integrada e incluindo os principais ambientais), a forma de gestão e produção. A produção e a sua engenharia é desafiada a integrar a qualidade, o bom desem- penho ambiental do processo produtivo e dos seus fornecedores nomeadamente numa lógica de cadeias de fornecimento.

Nesse sentido destaca-se as oportunidades que a avaliação ambiental de ciclo de vida, avaliação dos custos de ciclo de vida, produção mais limpa, gestão de cadeiras de fornecimento sustentáveis e ecologia industrial podem potenciar, levando a que a produção das soluções construtivas e a engenharia de produção seja uma fator decisivo dessa procura de sustentabilidade, reduzindo os efeitos ambientais negativos, valorizando o serviço dos ecossistemas e potenciando um equilíbrio nos custos logo uma sustentabilidade eficiente, na lógica do sugerido pelo LiderA.

A abordagem sugerida pela LiderA permite, assim, uma procura eficiente da sustentabilidade, assegurando uma procura de custos ajustada a cada realidade (DAVID LANGDON, 2007; KATS, 2010; WORLD GBC, 2013; PINHEIRO, 2014,), num caminho para a procura da sustentabilidade cada vez mais forte (AYRES, 2001).

\section{Conclusões}

A construção tem grande importância e grande impacto, desafiando cada vez mais os promotores, construtores, projetistas e gestores a procurarem uma abordagem que integre o bom desempenho ambiental, social e econômico, isto é a construção sustentável. A necessidade de procurar essa sustentabilidade na construção tem levado ao desenvolvimento de sistemas de avaliação e certificação, como o LEED e AQUA. Neste artigo apresenta-se um sistema 
menos conhecido no Brasil que é o sistema LiderA.

O LiderA é um sistema desenvolvido originalmente na língua Portuguesa e aplicada de forma alargada em Portugal e tem vindo a ser aplicado em vários países lusófonos, incluindo embora de forma reduzida também no Brasil. O sistema LiderA assenta numa abordagem que considera não apenas o desempenho ambiental, mas também o socioeconômico, sendo por isso um sistema para apoio à procura da sustentabilidade, contribuindo para interligar as construções e seus utilizadores.

A versão existente internacional, que utiliza vinte e dois critérios (ambientais e socioeconômicos) foi precisada (1) experimentalmente à realidade brasileira por meio de um estudo de benchmark e desenvolvimento de limiares (funções que definem os fatores de 0 a 10 e respectivas classes de $\mathrm{G}$ a $\mathrm{A}+$ onde $\mathrm{E}$ é um fator 1 ou prática de referência e A um fator 2 ou melhoria de $50 \%$ ) ajustados ao tipo de hotel e região.

Uma análise das duas aplicações do LiderA ao dois hotéis do Rio de Janeiro revela: (2) a capacidade do sistema de efetuar a avaliação do nível de desempenho e posicionar os hotéis. Evidencia (3) que os hotéis em questão dispõe já de um conjunto de boas práticas face a unidades hoteleiras no Brasil desta tipologia tendo atingindo a classe A (50\% face à prática de referencia). Por outro lado a escala alargada identifica (4) intervenções de melhoria que podem ajudar os hotéis ainda a melhorar significativamente o seu desempenho.

As preocupações dos empreendimentos nos casos resultou no bom desempenho ambiental decorrente de condições construtivas, boas práticas ambientais, e na procura de otimizar os seus desempenhos durante a fase de operação. Destaca-se ainda que com a aplicação de relativas melhorias poderiam passar para um nível ótimo e exemplar em termos ambientais e sustentáveis. Assim para assegurar um bom desempenho importa que se conjugue (5) as soluções construtivas, sistemas de equipamentos e modos de gestão mais ambiental.

Em conclusão a aplicação experimental do LiderA a dois hotéis no Brasil evidencia que consegue contribuir para posicionar a respectiva procura da sustentabilidade sendo por isso instrumento útil a utilizar quer na procura de sustentabilidade nos edifícios quer nas suas melhorias.

Entre os desenvolvimentos futuros é de referir o alargar da aplicação a um número mais vasto de casos e em diferentes zonas do Brasil, incluindo a aplicação a zonas urbanas brasileiras, que muito pode ajudar neste caminho fundamental da sustentabilidade. Bem como a ecoparques para os quais a engenharia de produção com as suas competências pode contribuir decisivamente na produção de materiais, construções e zonas mais ecológicas e sustentáveis e viáveis economicamente de forma sinérgica.

\section{Agradecimentos}

Os autores deste trabalho externam a sua gratidão a todos os assessores do Sistema LiderA, pelo trabalho primoroso no âmbito da susten- 
tabilidade na construção. Agradecemos também o apoio financeiro do Programa de Educação Tutorial - PET e do programa Ciência sem Fronteiras, ambos do Governo Federal, com a concessão de bolsas de estudo.

\section{Referências}

AYRES, R., BERRGH, J. van den, \& GOWDY, J. Strong versus weak sustainability: Economics, natural sciences, and consilience. 2001. Retrieved from http://philpapers.org/rec/AYRSVW

DAVIS LANGDON. Cost of Green Revisited: Reexamining the Feasibility and Cost Impact of Sustainable Design in the Light of Increased Market Adoption. 2007. (p. 25).

GALÃO, F. Hotel Marina All Suites, Rio de Janeiro - Avaliação de Posicionamento do Desempenho Ambiental - Relatório LiderA. Instituto Superior Técnico, Universidade Técnica de Lisboa, Janeiro 2013, 43 páginas, Lisboa.

GALÃO, F. Hotel Marina Palace, Rio de Janeiro - Avaliação de Posicionamento do Desempenho Ambiental - Relatório LiderA. Instituto Superior Técnico, Universidade Técnica de Lisboa, Janeiro 2013, 43 f. Lisboa.

KATS, G. Greening Our Built World: Costs, Benefits, and Strategies. 2010. (p. 280). Island Press. Retrieved from http://www.amazon.co.uk/Greening-OurBuilt-World-Strategies/dp/159726668X

KIBERT, C. Policy instruments for a sustainable built environment. J. Land Use \& Envtl. L, 2003. 17(2), 379-394. Retrieved from http://www.law.fsu.edu/journals/landuse/vol 17_2/kibert.pdf

KIBERT C. J. Sustainable Construction: Green Building Design and Delivery - Third Edition. 2013. (p. 562). Wiley. Retrieved from http://www.amazon.com/Sustainable-

Construction-Building-Design-

Delivery/dp/0470904453

LEITE, V. F. Certificação Ambiental Na Cons- trução Civil - Sistemas Leed E Aqua. 2011. 59f. Monografia. Escola de engenharia - Universidade Federal de Minas Gerais, Belo Horizonte, 2011.

LUTZ, C.; PIRES, D.; MORAeS, C. Parques Industriais Ecológicos como instrumento para o desenvolvimento sustentável do estado do Rio Grande do Sul. Estudos Tecnológicos em Engenharia, 9(1):37-51, janeirojunho 2013. Brasil.

PEREIRA, P. I. Construção Sustentável: o desafio. 2009. 106 f. Monografia (Licenciatura em Engenharia Civil) - Universidade Fernando Pessoa, Porto, 2009. Disponível em: < http://bdigital.ufp.pt/bitstream/10284/2674/ 3/T_13485.pdf>. Acesso em: 27 mar. 2013.

PINHEIRO, M. D. Construção Sustentável Mito Ou Realidade?. 2003. In: VII Congresso Nacional de Engenharia do Ambiente. Lisboa. Portugal.

PINHEIRO, M. D. Ambiente e Construção Sustentável. 1 ed. Portugal: Instituto do Ambiente. 2006. 243 p. ISBN 972-8577-32-X

PINHEIRO, M. D. LiderA: Sistema Voluntário Para A Sustentabilidade Dos Ambientes Construídos. Versão 2.00c. 2011. 48p, LiderA, Lisboa.

PINHEIRO, M. D. Manual Para Projectos De Licenciamento Com Sustentabilidade Segundo O Sistema LiderA. 1 ${ }^{a}$ edição digital. 2010. 43p, LiderA, Lisboa. ISBN 978-98996922-0-6

PINHEIRO, M. D. Imobiliário sustentável. Mudar de paradigma e integrar a sustentabilidade de forma proativa. 2014. 286 páginas. Vida Imobiliária, Porto, Portugal.

PLESSIS, C., \& Cole, R. J. Motivating change: shifting the paradigm. Building Research \& Information, $2011 \quad 39(5), \quad$ 436-449. doi:10.1080/09613218.2011.582697

VEIGA, L.B. V. \& MAGRINI, A., 2009. Ecoindustrial park development in Rio de Janeiro, Brazil: a tool for sustainable development. Journal of Cleaner Production, 17(7), pp.653-661. Available at: http://www.sciencedirect.com/science/article / pii/S095965260800293X [Accessed August 21, 2014]. 
WORLD GBC. The Business Case for Green Building. A Review of the Costs and Benefits for Developers, Investors and Occupants. 2013. (p. 124). Retrieved from http://www.worldgbc.org/activities/businesscase/ 